\title{
Estimación de la Validez de Constructo y Consistencia Interna de la Escala de Impacto de las Imágenes Femeninas Presentadas por los Medios de Comunicación sobre Adolescentes Mujeres."
}

\section{Construct Validity and Reliability of an Instrument to Assess the Impact of Female Images Presented by the Mass Media on Female Adolescents.}

\author{
M. Elena Larraín Sundt \\ Javier Camus Yasna Orellana Montserrat Arrieta
}

Universidad de los Andes, Chile

(Rec: 31 diciembre 2008 Acep: 23 de abril 2009)

\begin{abstract}
Resumen
Se presentan los resultados obtenidos de la estimación de la consistencia interna y la validez de constructo de la escala de Impacto de las Imágenes Femeninas presentadas por los medios de comunicación sobre Adolescentes Mujeres (IMAMIF) de Larraín, Camus, Orellana y Arrieta, en una muestra de 662 adolescentes de Santiago de Chile. Es un cuestionario de 45 afirmaciones que se evalúa a través de 5 alternativas de respuesta $(1=$ nunca; $5=$ siempre). Se encontró una alta consistencia interna (Alfa de Cronbach 0.969). A través del Análisis Factorial Exploratorio con el método de Factores Principales (AFP), se encontró una estructura conformada por tres factores (Dieta patológica, Disconformidad corporal y Objetivación del cuerpo). En conjunto, estos tres factores explican el $84.11 \%$ de la estructura de correlación de las variables originales. Palabras Clave: Imágenes femeninas, medios de comunicación, imagen corporal, validez, confiabilidad.
\end{abstract}

\begin{abstract}
This paper aimed to estimate reliability and construct validity of an instrument to assess the impact of female images presented by the mass media on body image of female adolescents (IMAMIF) of Larraín, Camus, Orellana and Arrieta, in a sample of 662 female adolescents. It is a questionnaire of 45 statements that evaluates the impact that female images presented by mass media, has on body image of adolescent girls. An overall Cronbach's alpha coefficient of 0.969 was obtained revealing a high internal consistency. Through an exploratory factorial analysis with principal factors it was found a structure conformed by three factors (Pathological Diet, Body Dissatisfaction and Self Objectivation). As a whole these 3 factors explain $84.11 \%$ of the correlational structure of the original variables.
\end{abstract}

Key words: Female images, mass media, body image, validity, reliability.

\footnotetext{
Proyecto financiado por el Fondo de Ayuda a la Investigación (FAI) de la Universidad de los Andes. PSI-003

Correspondencia a : mlarrain@uandes.cl, javiercamush@gmail.com, yorellana@uandes.cl,montsearrieta@gmail.com
} 


\section{Introducción}

Los conceptos de belleza, de fealdad y de lo que se concibe atractivo y sensual, han variado a lo largo de la historia. La mujer y el cuerpo considerado bello han sufrido importantes cambios en las diversas épocas desde cuerpos redondeados y curvilíneos a estructuras corporales rectilíneas y extremadamente delgadas (Eco, 2004, 2007; Sypeck, Grey \& Ahrens, 2004). La sociedad actual comunica de manera reiterada y a través de diversas vías, que el papel más importante de la mujer es ser atractiva físicamente. Los medios de comunicación perpetúan y refuerzan esta idea sugiriendo que la totalidad de la mujer se expresa, de modo casi exclusivo, a través de la imagen corporal (González $\&$ Bovone, 2007). Esto ha llevado a una objetivación y a una erotización del cuerpo femenino. El concepto de autoobjetivación ha sido citado en varias investigaciones en los últimos años (Calogero, 2004; Fredrickson \& Roberts, 1997; Fredrickson, Roberts, Noll, Quinn, \& Twenge, 1998; Melbye, 2007; Molt \& Conroy, 2000; Roberts, \& Gettman, 2004; Tiggemann \& Lynch, 2001) y alude al grado en que las personas internalizan los estándares físicos culturales externos y la sexualización del cuerpo -el cuerpo como objeto- haciendo que pasen a ser propios. Los mensajes transmitidos por los medios de comunicación implícitamente estimulan la disconformidad con el propio cuerpo si éste no se ajusta al ideal propuesto, aumentan el nivel de comparación y disminuyen la valoración personal en directa proporción con la evaluación negativa (Melbye, 2007).

Como complemento a lo ya planteado, actualmente se aprecia un aumento de dietas restrictivas patológicas (Casper \& Offer, 1990), del uso de ejercicios físicos, de laxantes y hasta de cirugías plásticas reductivas (Bonelli, 2007) como medios para mantener el cuerpo deseado y valorado.

El impacto que las imágenes femeninas ofrecidas por la sociedad actual tiene sobre el desarrollo psicológico de las adolescentes, es un tema de relevancia social que requería contar con un instrumento ad hoc que evaluara algunas de las dimensiones que la literatura reporta como áreas afectadas. Las tres dimensiones que se relacionaron con el ideal corporal femenino, presentado por los medios de comunicación, fueron: dieta patológica, disconformidad corporal y erotización u objetivación del cuerpo. Un instrumento que relacionase estas variables no ha sido publicado en nuestro país, hasta donde hemos podido conocer. De allí que en este trabajo se presente un estudio de la validez de contenido, de constructo y la consistencia interna de un instrumento orientado a medir estas influencias. La focalización en adolescentes se debe a que por la etapa del desarrollo en que se encuentran, son consideradas el grupo más vulnerable a estos influjos. Las adolescentes son afectadas y presionadas por el ideal corporal femenino transmitido a través de las imágenes que los medios de comunicación presentan y esto constituye un factor de riesgo para la génesis de sintomatología de diverso tipo (ansiosa, depresiva o alteraciones de la conducta alimentaria) dado que se encuentran aún en proceso de definir su autoconcepto e identidad, los que involucran la relación con el propio cuerpo (Akhtar, 1992, 2003; Akhtar, \& Samuel, 1996; Kroger, 2000).

La formación de la identidad se desarrolla desde el exterior hacia el interior (Doltó, 1990). Esta es la principal razón del por qué las figuras de identificación y los modelos, la apariencia, el estilo personal, la relación con el propio cuerpo, la imagen corporal y todos los fenómenos relacionados son tan cruciales durante la adolescencia temprana (Larraín, 2007). Melbye (2007) plantea como variables medulares del fenómeno de centrarse en el cuerpo y de objetivarlo, el auto-monitoreo y la vergüenza. Según sus planteamientos, la vergüenza tendría relación con sentimientos de culpa por no lograr estándares culturales y también sería una medición de cuánto la mujer ha logrado internalizar estos ideales físicos que la sociedad le presenta. El auto-monitoreo, por su parte, aludiría a la manera en que la persona desarrolla una actitud vigilante hacia su cuerpo en función de la comparación con los estándares que la cultura propone como ideales de belleza (Melbye, 2007).

Como muchos adultos, las preadolescentes y adolescentes creen que la aceptación y la popularidad están correlacionadas con una figura y tipo corporales deseables (Gable \& Kearney, 1998 en Akos \& Levitt, 2002). Tienen un amplio deseo de perder peso o lograr un tipo corporal distinto para ser aceptadas y gustar a los pares del mismo sexo o del sexo contrario (Ricciardelli \& McCabe, 2001). Se sabe que las actitudes y opiniones subjetivas sobre el peso, como mayor al real, y la autopercepción del cuerpo tienen un valor predictivo respecto de las conductas de dietas y distorsiones en la imagen corporal (Cullari, Vosbug, Shotwell, Inzodda, Davenport, 2002; Fallon \& Rozin, 1985; Salusso-Deonier \& Schwartzkopft, 1991 en Cullari, Rohrer, Bahm, 1998; Simmons, L. \& Blyth, 1987).

\section{Influencia de los cánones de belleza presentados por los medios de comunicación sobre el ideal corporal}

Anderson, R. \& Pempek, T. (2005) estiman que el estadounidense promedio es bombardeado con más de mil avisos por día. La mayoría de estos avisos promueven y relacionan la sexualidad con la belleza y la extrema delgadez en las mujeres. Muchas mujeres tienen, por lo tanto, la creencia errónea de que tienen que ser muy delgadas y que su atractivo sexual es central. Debido a que el concepto que tienen las adolescentes mujeres sobre sí mismas está tan relacionado con la percepción de su atractivo, las influencias y retroalimentación que reciben de sus mejores amigas y sus madres son importantes predictores de las estrategias que utilizarán para aceptar o intentar 
cambiar sus cuerpos (Bonelli, 2007). En esta misma línea, el reporte de la Asociación Psicológica Americana (APA 2007) enfatiza que la progresiva y cada vez más temprana sexualización de las niñas da cuenta del enorme impacto que la publicidad tiene sobre la objetivación y erotización del cuerpo adolescente.

La influencia de la exposición a la publicidad va a depender del nivel de automonitoreo de las jóvenes y el juicio sobre la belleza corporal personal dependerá, a su vez y en gran medida, del nivel de automonitoreo (Henderson \& King, 1997 en Díaz, Pandolfi, \& Perfetti, 1999). Melbye (2005) establece que las adolescentes mujeres que tienen un alto automonitoreo, serán más susceptibles a la presión cultural y a los ideales de belleza impuestos externamente y tendrán niveles de autoestima corporal menores.

\section{Disconformidad Corporal y Dieta Patológica}

Los medios masivos de comunicación proponen un ideal corporal y un ideal de bellaza esbelto. De este modo, estos medios se constituyen en el factor sociocultural más potente para el desarrollo de la disconformidad corporal (Cullari et al., 1998; Groesz, Levine, \& Murnen, 2002, en Bardonecone \& Cass, 2006). Es sabido que la disconformidad corporal comienza a una edad bastante temprana, alrededor del inicio de la pubertad o incluso antes (Rauste-von Wright, 1989 en Cullari et al., 2002) y que estos sentimientos son una fuente de emociones negativas acerca del crecimiento como un todo (Brumberg, 1997; Heartherton, Mahamedi, Striepe, Field \& Keel, 1997 en Cullari, et al. 2002; Pesa et al., 2000 en Akos \& Levitt 2002). El estudio de Tiggerman \& Slater (2004) muestra con claridad cómo mujeres que son expuestas a ver imágenes idealizadas en video clips musicales, desarrollaron actitudes de comparación social y mayor disconformidad corporal que aquellas que no estuvieron expuestas. La "Teoría de la Comparación Social" sugiere que los medios de comunicación masivos son, generalmente, utilizados como medios de autoevaluación. Esta incluye en uno de sus aspectos el "atractivo físico", que es comparado con el presentado por las modelos "aparentemente" superiores en este aspecto (Thomsen, McCoy \& Williams, 2001; Tiggerman \& McGill, 2004).

La disconformidad con el propio cuerpo es parte central de los trastornos de la conducta alimentaria, los que a su vez han aumentado en prevalencia (Thomsen et al., 2001; APA, 2007). En Chile, Correa, Zubarew, Silva y Romero (2006) establecieron que la prevalencia de los Trastornos de conducta alimentaria en niñas escolares de la Región Metropolitana de 11 a 19 años es de un $11.3 \%$ para el nivel socioeconómico bajo, un $8.3 \%$ para el nivel socioeconómico medio y un $5.1 \%$ para el nivel socioeconómico alto. La prevalencia de tener un Trastorno de la Conducta Alimentaria para la Región Metropolitana fue de 8.3\% (Correa et al., 2006). La disconformidad corporal es el factor que predice con mayor fuerza la sintomatología de los desórdenes alimenticios (Graber, Archibald, \& Brooks-Gunn, 1999; Franko \& Omori, 1999; Leon, Fulkerson, Perry \& Cudeck, 1993 en Akos y Levit, 2002). La insatisfacción corporal durante la pubertad podría predisponer al adolescente a desarrollar problemas alimenticios en la adolescencia media o tardía (Attic \& Brooks-Gunn, en Akos \& Levitt, 2002; Pinhas, Toner, Ali, Garfinkel, \& Stuckless, 1999). Es también significativo que la imagen corporal, más que el perfeccionismo internalizado o sentimientos de ineficacia, sirve como un predictor longitudinal de problemas alimenticios (Attie \& Brooks-Gunn, 1989 en Akos y Levitt, 2002).

\section{Actitudes femeninas erotizadas y objetivación del cuerpo}

El reporte de la APA (2007), sobre la sexualización de las niñas, muestra cómo va de la mano con diferentes patologías psiquiátricas, incluido los trastornos de la conducta alimentaria, al favorecer la formación de una imagen corporal distorsionada.

Por otro lado, la sexualización de las niñas influye en la formación de la identidad, dado que ésta se desarrolla también en función de la "máscara" social que muestran. Asumiendo que las niñas pueden estar desarrollando su identidad en parte a través de las ropas y vestimenta que escogen, es preocupante que a edades tempranas ellas sean invitadas a probarse y usar ropas diseñadas para resaltar la sexualidad femenina, todo esto obviamente a través de un cuerpo delgado (APA, 2007).

Hoy nos encontramos inmersos en la era de la apariencia, de seguir a ciegas la moda y sus frecuentes cambios. Cada joven busca su "look", que es como su identidad de plástico. En esta situación es donde existe el riesgo de que se disuelvan las diferencias entre interioridad y exterioridad, llegando incluso a la indiferenciación entre el cuerpo humano y los objetos (Herreros, 2002).

Los esquemas y las creencias sobre la objetivación y la sexualización del cuerpo pueden operar de un modo implícito y automático (Dasgupta \& Asgari, 2004) en la psiquis de las jóvenes. La sexualización ocurre cuando el valor de una persona proviene fundamentalmente de sus atributos sexuales con exclusión de otras características (APA, 2007). También cuando una persona está expuesta a un canon de belleza que equipara atractivo físico (definido de manera muy estrecha) con ser "sexy". A esto se agrega que una persona estará siendo erotizada o considerada como un objeto sexual, es decir, objetivada sexualmente, para que otros puedan usarla como una "cosa" u objeto sexual. En la sociedad actual, a la mujer se la ve y se la usa como objeto de atractivo erótico y se aprecia una falta de reconocimiento de la igual dignidad entre varón y mujer (Castilla \& Cortazar, B., 1997,1996). La educación escolar en torno a estas cuestiones es por lo tanto crucial. La visión de la mujer como objeto sexual y el valor otorgado al cuerpo puede 
variar de acuerdo al proyecto educativo de cada establecimiento educacional (Salomone, R., 2003; Aguirre, M.E., 2006). Colegios de orientación laica versus aquellos que incorporan elementos de la antropología femenina dentro de un marco de valores religiosos y en concreto cristianos pueden por lo tanto entregar visiones diversas sobre el valor de la mujer, el desarrollo femenino, la feminidad y el pudor (Castilla \& Cortazar, 1997,1996). La antropología cristiana entiende con especial profundidad la perversión que supone maltratar a cualquier persona, varón o mujer (Choza, 1988). Los medios de comunicación comercian actualmente con el cuerpo de la mujer, considerándola como cosa, no como persona y asimismo estos valores pueden ser o no transmitidos de manera diferente en cada contexto educativo.

En Chile, Marín (2002) señala, en concordancia con estos planteamientos, que parte del origen de los trastornos de la conducta alimentaria radica en que la sociedad devalúa la experiencia y los valores de la mujer, objetivando su cuerpo. Sugiere que la tarea preventiva debiera vincularse con estimular el uso más selectivo de los medios de comunicación social, los que colocan su atención en la figura corporal y así favorecen la distorsión de la imagen corporal. Por su parte, en otro estudio chileno, Behar; De la Barrera y Michelotti (2000), también atribuyen importancia a la exposición a los medios de comunicación y a la presión que éstos ejercen sobre las jóvenes en cuanto al ideal de delgadez y a la socialización del rol sexual.

La literatura (APA, 2007) describe además otras consecuencias para las niñas que han estado expuestas a imágenes de mujeres sexualizadas y objetivadas y que han internalizado estos valores. Se indica que niñas de colegios mixtos tienden a tener peores rendimientos académicos de tipo cognitivo y también físico (por ejemplo en clases de gimnasia) al estar rodeadas de hombres en el horario escolar. También se describe como una de las más graves consecuencias de la autoobjetivación, la fragmentación de la conciencia, es decir, la atención crónica a la apariencia física, la que deja menores recursos cognitivos disponibles para otras actividades mentales y físicas (APA, 2007).

\section{Método}

\section{Participantes}

La población de interés correspondió a jóvenes adolescentes mujeres de entre 11 y 18 años, que asistían al establecimiento educacional en forma regular en la Región Metropolitana (RM) de Santiago de Chile. La muestra de este estudio fue intencionada y estuvo constituida en una primera etapa por 7 establecimientos educacionales pertenecientes a los tres niveles socioeconómicos definidos según SIMCE (2004), con regímenes de enseñanza de tipo laico o religioso y/o de tipo mixto y no mixto. La muestra de estudiantes adolescentes estuvo conformada por todas las alumnas de los cursos de séptimo básico, primero y tercero medio que aceptaron participar en la investigación y que contestaron el instrumento en una modalidad colectiva. Cada participante aceptó voluntariamente colaborar en la investigación.

Inicialmente se conformó una muestra de 710 adolescentes. Las edades de las jóvenes de séptimo año fluctuaban entre los 11 y 14 años, quienes cursaban primer año medio tenían edades comprendidas entre 13 y 17 años y quienes pertenecían a tercero medio edades que se encontraban entre los 15 y 18 años. Hubo 8 adolescentes (1.1\%) que no contestaron o invalidaron su edad en el cuestionario objeto de estudio. Asimismo, hubo pérdida en la muestra debido a la falta de respuesta o respuestas nulas en uno o varios reactivos. Finalmente, la muestra quedó conformada por 662 adolescentes con cuestionarios válidos que fueron completados en su totalidad. Con esta muestra se realizó la validación del cuestionario.

\section{Procedimiento}

Para la construcción del instrumento (IMAMIF) se elaboraron 90 reactivos considerando las dimensiones de dieta patológica, disconformidad corporal y erotización u objetivación del cuerpo. Cada ítem relacionaba en su contenido la respectiva dimensión con el ideal corporal femenino tal cual es presentado por los medios de comunicación. Estos ítemes recibieron el acuerdo de 5 jueces expertos en la codificación de cada respuesta. El acuerdo entre los jueces fue respecto de los siguientes criterios: claridad de redacción del ítem, pertinencia del ítem a la edad de la muestra y adecuación del contenido del ítem a una de las tres dimensiones estudiadas. El instrumento es una escala tipo Likert, donde la respuesta es graduada en categorías que representan frecuencias. El supuesto a la base es que los deseos, anhelos, temores y actitudes se reflejarán en el contenido de las respuestas de los individuos (Aiken, 1996).

Luego los 90 reactivos se sometieron a una aplicación piloto en 14 adolescentes entre 12 y 18 años. Se decidió eliminar 8 ítemes porque su redacción resultó confusa para las encuestadas. El instrumento con 82 reactivos fue sometido a la revisión de 5 jueces expertos quienes evaluaron cada ítem de acuerdo a los criterios arriba mencionados. Cada ítem debía mostrar una consistencia interjueces de al menos $80 \%$ para ser incluido. Finalmente se seleccionó los 54 ítemes definitivos. La manera de contestar era la siguiente: 1) nunca (1 punto); 2) casi nunca (2 puntos); 3 ) a veces (3 puntos); 4) casi siempre (4 puntos); y 5) siempre (5 puntos). El rango teórico de los puntajes podía fluctuar entre 54 y 270 puntos. Los puntajes mayores apuntaban a un mayor impacto de las imágenes femeninas presentadas por los medios de comunicación sobre las tres dimensiones descritas, mientras que los más bajos señalaban un menor impacto. 


\section{Resultados}

Para todos los análisis se utilizaron los paquetes estadísticos SAS versión 9.1 y STATA en su versión 10.0. Inicialmente se realizó un análisis descriptivo de los datos, para luego continuar con un análisis factorial exploratorio a través del método de factores principales de la matriz de correlación policórica de los reactivos que constituían las preguntas del cuestionario IMAMIF. Una vez extraídos los factores principales definitivos se realizaron test no paramétricos de Kruskal Wallis de igualdad de medianas para comparar los puntajes totales obtenidos en las puntuaciones según las agrupaciones de reactivos por factor y también para la puntuación del cuestionario con la totalidad de los reactivos finales en las distintas estratificaciones realizadas en la muestra, a fin de observar si existen diferencias significativas en los distintos estratos.

El puntaje total del cuestionario teóricamente podía fluctuar entre 54 y 270 puntos, pero en la muestra se observó como mínimo 54 puntos y como máximo 253 puntos. Se obtuvo una mediana de 110 puntos con un rango intercuartílico de 199 puntos. Esta gran variabilidad observada en los puntajes extremos pudo deberse a que la muestra correspondía a alumnas de establecimientos educacionales y no a población consultante.

Se observa en la Figura 1 la distribución de los puntajes totales del IMAMIF, los cuales representan una distribución asimétrica (skewness $=0.84$ ), asentadas sobre un amplio rango de puntajes.

En la Tabla 1 se presenta la distribución según nivel socioeconómico, tipo de establecimiento educacional y régimen del establecimiento educacional, del total de 662 niñas que respondieron el cuestionario completo. Una primera descripción de la muestra indica que $325(49.1 \%)$ adolescentes pertenecían a establecimientos educacionales de régimen laico y 337 (50.9\%) a establecimientos educacionales de régimen religioso. Del total de niñas, 211 (31, 9\%) adolescentes pertenecen al NSE alto, $233(35,2 \%)$ al NSE medio y $235(32,9 \%)$ a un NSE bajo.

Del total de establecimientos educacionales de régimen laico, 121 niñas (37.23\%) provenían de colegios mixtos y $204(62.77 \%)$ de establecimientos educacionales de niñas. En el caso de los establecimientos educacionales religiosos, 161 adolescentes $(47.77 \%)$ provenían de establecimientos educacionales mixtos y 176 de establecimientos educacionales de niñas $(52.23 \%)$.

Como se observa en la Tabla 2, la muestra quedó conformada equitativamente por aproximadamente igual cantidad de adolescentes para los distintos cursos que la conformaban. Se aprecia una distribución uniforme con una leve diferencia de alrededor de un $1.66 \%$ menos en las alumnas de tercer año medio.

\section{Análisis de factores}

En primer lugar se considera la matriz de correlación policórica de los reactivos que compusieron el cuestionario. Estos coeficientes se justifican bajo el supuesto que el conjunto de reactivos medidos en escala ordinal proviene de la categorización de variables continuas latentes que se asumen con distribución normal (Panter, Swygert, Dahlstrom, \& Tanaka, 1997), de tal manera de sustentar un adecuado análisis factorial exploratorio (AFE). La matriz policórica de los 54 reactivos que componían el cuestionario fue

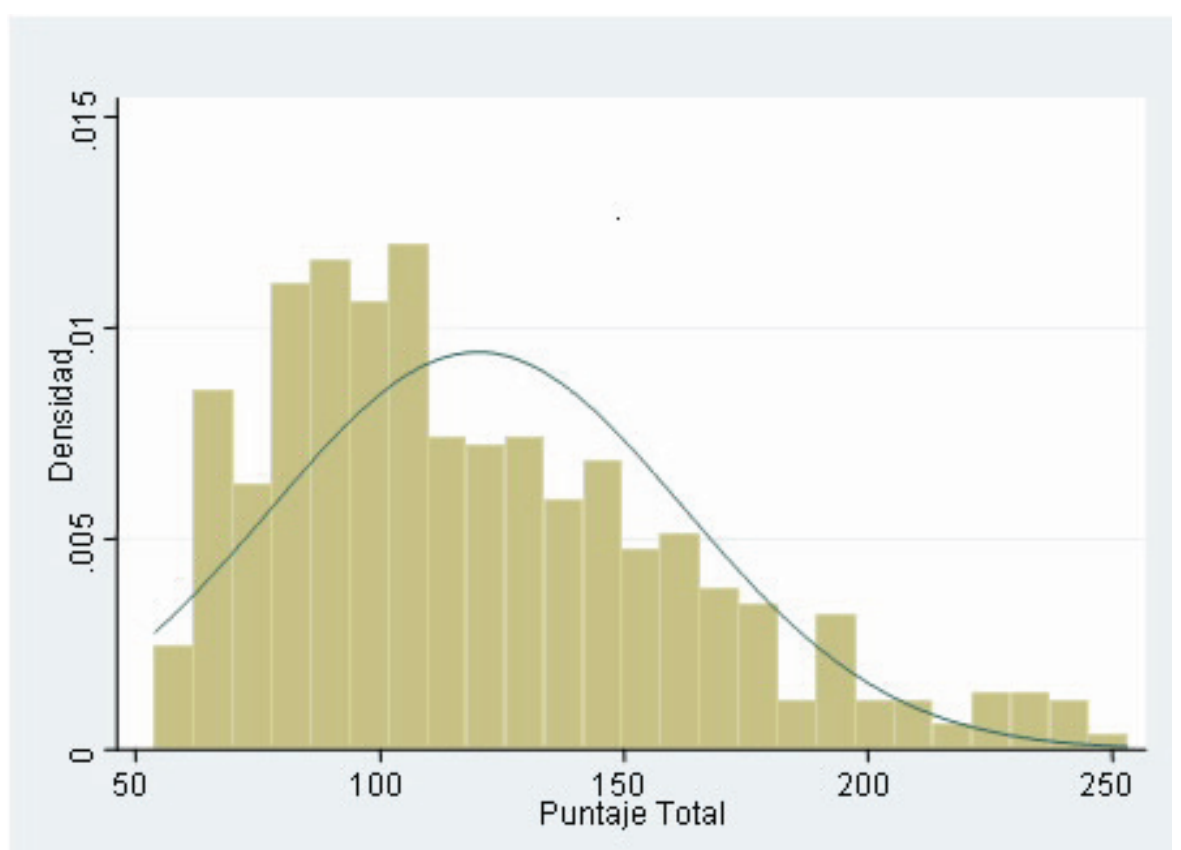

Figura 1. Histograma de la distribución de puntajes totales de la IMAMIF 
Tabla 1. Distribución según nivel socioeconómico-tipo de establecimiento educacional y régimen del establecimiento educacional

\begin{tabular}{lllcl}
\hline NSE & Tipo & Laico & Régimen \\
& & & Religioso & Total \\
\hline Alto & mixto & & & $106(50,2 \%)$ \\
& No mixto & $49(46,2 \%)$ & $57(53,8 \%)$ & $105(49,8 \%)$ \\
& total & $52(49,5 \%)$ & $53(50,5 \%)$ & $211(100 \%)$ \\
Medio & mixto & $101(47,4 \%)$ & $110(52,1 \%)$ & $116(49,8 \%)$ \\
& No mixto & & & $117(50,2 \%)$ \\
& total & $55(47,4 \%)$ & $61(52,6 \%)$ & $233(100 \%)$ \\
& & $58(49,6 \%)$ & $59(50,4 \%)$ & $60(27,5 \%)$ \\
& mixto & $113(48,5 \%)$ & $120(51,5 \%)$ & $158(72,5 \%)$ \\
& No mixto & & & $218(100 \%)$ \\
& total & $17(28,3 \%)$ & $43(71,7 \%)$ & $662(100 \%)$ \\
\hline
\end{tabular}

Tabla 2. Distribución según curso

\begin{tabular}{ccc}
\hline Curso & Frecuencia de adolescentes \\
\hline $7^{\mathrm{o}}$ & $224(33,84 \%)$ \\
$\mathrm{I}^{\mathrm{o}}$ & $225(33,99 \%)$ \\
$\mathrm{III}^{\mathrm{o}}$ & $213(32,18 \%)$ \\
\hline
\end{tabular}

obtenida a través de una macro en el software SAS en su versión 9.1. Los coeficientes de correlación policórica fueron todos significativos $(\mathrm{p}<0.05)$, lo que permitió justificar la aplicación de un análisis factorial exploratorio que se realizó a través del método de Factores Principales (AFP).

Al realizar el AFP sin rotación se obtuvo un total de 4 factores comunes utilizando el criterio de eigenvalue $>1$ (Tabla 3). Este conjunto de cuatro factores explicaron un $85.49 \%$ de la estructura de correlaciones existentes entre las variables originales.

El primer factor principal explicaba por sí sólo un $69.55 \%$ de la variabilidad total y los tres siguientes factores extraídos en orden decreciente explicaban por sí sólos un $8.8 \%, 5,7 \%$ y un $2,9 \%$ respectivamente de la relación existente entre las variables originales.

Es interesante mencionar que existen técnicamente 3 factores que se destacan del resto y que en conjunto explican un $82,58 \%$ de la estructura de correlación existente entre las variables originales. Esto es consistente con la idea original de los autores, quienes pretendían medir a través del cuestionario tres dimensiones: disconformidad corporal, dieta patológica y objetivación del cuerpo.

Si bien el gráfico de sedimentación muestra claramente que son tres los factores que destacan, se decidió realizar una rotación varimax que permitiera comprobar lo anterior. Además, este análisis favorecería dar una mejor interpretación a los factores extraídos. El resultado de la aplicación de la rotación varimax entregó la extracción de 3 nuevos factores, que explicaron individualmente un $32.77 \%, 31.13 \%$ y $20.21 \%$ de la estructura de correlación existente de las variables originales. En esta extracción se observó que del total de 54 reactivos, en general en las comunalidades era posible apreciar que gran parte de la variabilidad de cada uno de los reactivos era explicada en un alto porcentaje por los tres factores comunes extraídos. Sólo los reactivos 22 y 53 eran explicados en un máximo de un $20 \%$ por los 3

Tabla 3. Porcentaje de la estructura de correlación explicada por los 4 factores originales extraídos

\begin{tabular}{cccc}
\hline Factor & Total & \% parcial explicado & \% acumulado \\
\hline 1 & 26,41 & 68,07 & 69,55 \\
2 & 3,42 & 8,8 & 76,9 \\
3 & 2,2 & 5,7 & 82,58 \\
4 & 1,1 & 2,9 & 85,49 \\
\hline
\end{tabular}


Figura 2. Gráfico de sedimentación del Análisis de Factores Principales (AFP)

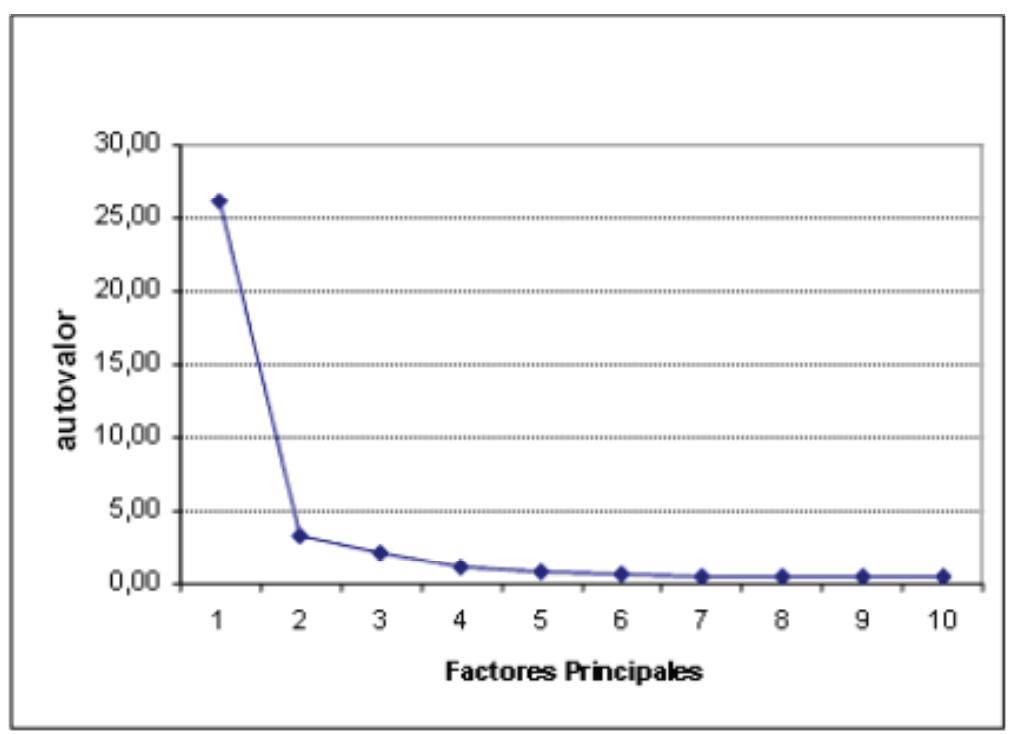

Tabla 4. Comunalidades de los 45 reactivos finales al extraer los 3 factores principales luego de una rotación varimax

\begin{tabular}{|c|c|c|c|}
\hline Reactivo & Comunalidad & Reactivo & Comunalidad \\
\hline 1 & 0,35 & 31 & 0,59 \\
\hline 3 & 0,56 & 32 & 0,65 \\
\hline 4 & 0,49 & 33 & 0,54 \\
\hline 6 & 0,51 & 34 & 0,72 \\
\hline 7 & 0,51 & 35 & 0,74 \\
\hline 8 & 0,51 & 36 & 0,71 \\
\hline 9 & 0,64 & 37 & 0,71 \\
\hline 11 & 0,71 & 38 & 0,69 \\
\hline 12 & 0,49 & 39 & 0,48 \\
\hline 15 & 0,71 & 40 & 0,67 \\
\hline 17 & 0,39 & 41 & 0,75 \\
\hline 18 & 0,46 & 42 & 0,55 \\
\hline 20 & 0,72 & 43 & 0,79 \\
\hline 21 & 0,62 & 44 & 0,73 \\
\hline 23 & 0,71 & 45 & 0,62 \\
\hline 24 & 0,63 & 46 & 0,70 \\
\hline 25 & 0,65 & 47 & 0,66 \\
\hline 26 & 0,77 & 48 & 0,33 \\
\hline 27 & 0,78 & 49 & 0,77 \\
\hline 28 & 0,74 & 50 & 0,33 \\
\hline 29 & 0,67 & 51 & 0,31 \\
\hline \multirow[t]{2}{*}{30} & 0,68 & 52 & 0,57 \\
\hline & & 54 & 0,73 \\
\hline
\end{tabular}


Tabla 5. Resumen de pesos factoriales de cada reactivo según factor de la matriz de estructura

\begin{tabular}{|c|c|c|c|}
\hline Factor & $\begin{array}{c}\text { Peso } \\
\text { Factorial } \\
\end{array}$ & Reactivo & Contenido \\
\hline \multirow{16}{*}{ Dieta Patológica } & 0,70 & 6 & Uso ropa suelta para que no se noten rasgos de mi cuerpo que me disgustan y me hacen sentir mal. \\
\hline & 0,61 & 7 & Me aflige que me quede mal la ropa de moda que llevan mis amigas y que muestran los medios de comunicación. \\
\hline & 0,77 & 11 & $\begin{array}{l}\text { Me incomoda pasearme por la playa en traje de baño porque creo que soy más gorda que el resto de las mujeres } \\
\text { que están ahí. }\end{array}$ \\
\hline & 0,53 & 12 & Me incomodaría usar una talla más grande que mis amigas. \\
\hline & 0,57 & 17 & $\begin{array}{l}\text { Generalmente no coincide la imagen física que yo tengo de mí, con la imagen física que tienen las personas que } \\
\text { me rodean. }\end{array}$ \\
\hline & 0,49 & 18 & $\begin{array}{l}\text { Cuando me compro una prenda de vestir, no quedo contenta si la talla que me queda bien es más grande de lo que } \\
\text { yo esperaba. }\end{array}$ \\
\hline & 0,73 & 25 & Siento que mi cuerpo no se adecúa al ideal de belleza existente hoy en día. \\
\hline & 0,78 & 28 & Pienso que mi cuerpo es más grande y grueso en comparación con mis amigas. \\
\hline & 0,73 & 29 & Generalmente me comparo con mis amigas cuando estamos frente al espejo y no me agrada como me veo. \\
\hline & 070 & 30 & Cuando voy a comprarme ropa, prefiero no ir con mis amigas porque siento que me voy a ver más gorda que ellas. \\
\hline & 0,66 & 35 & $\begin{array}{l}\text { No estoy conforme con mi cuerpo porque pienso que debería parecerse más al cuerpo de las mujeres que veo en } \\
\text { las revistas o diarios. }\end{array}$ \\
\hline & 0,67 & 36 & Creo que si bajara de peso me sentiría más cómoda conmigo misma. \\
\hline & 0,70 & 41 & Cuando veo a una mujer publicitando ropa y me comparo con ella, me siento mal con mi cuerpo. \\
\hline & 0,63 & 42 & Me enojo, o me da rabia, cuando la ropa que uso no me queda como me gustaría. \\
\hline & 0,74 & 46 & $\begin{array}{l}\text { Evito situaciones en que las personas pudieran ver mi cuerpo, porque pienso que éste no se adecua a la delgadez } \\
\text { que se usa hoy en día. }\end{array}$ \\
\hline & 0,61 & 52 & Ciertas características poco atractivas de mi cuerpo me ponen incómoda cuando estoy en situaciones sociales. \\
\hline \multirow{16}{*}{$\begin{array}{l}\text { Disconformidad } \\
\text { Corporal }\end{array}$} & 0,52 & 1 & $\begin{array}{l}\text { Me fijo más en una revista, en un video clip o en un programa de televisión si incluye temas tales como dieta y } \\
\text { moda. }\end{array}$ \\
\hline & 0,67 & 3 & Cuando hago ejercicio, pienso en quemar más calorías y así poder ponerme la ropa que está de moda. \\
\hline & 0,67 & 4 & Me preocupo constantemente de saber las calorías que tienen los alimentos que consumo, para no sobrepasarme. \\
\hline & 0,60 & 8 & Hago ejercicios para que mi cuerpo se vea sensual o sexy. \\
\hline & 0,58 & 9 & $\begin{array}{l}\text { Me preocupo mucho de mi cuerpo, porque quiero alcanzar la sensualidad de las personas que aparecen en revistas } \\
\text { y televisión. }\end{array}$ \\
\hline & 0,71 & 20 & Antes de comprarme ropa me preocupo de hacer dieta estricta. \\
\hline & 0,65 & 21 & $\begin{array}{l}\text { Hago ejercicio físico imaginándome que voy a lograr tener el cuerpo de las mujeres que salen en la televisión y } \\
\text { las películas. }\end{array}$ \\
\hline & 0,64 & 26 & $\begin{array}{l}\text { Me siento culpable cuando como en exceso porque siento que así no podré tener el cuerpo delgado que muestran } \\
\text { los medios de comunicación. }\end{array}$ \\
\hline & 0,77 & 27 & Hago dieta a menudo, para conseguir un cuerpo que luzca bien con la ropa que está de moda. \\
\hline & 0,66 & 31 & $\begin{array}{l}\text { Intento seguir los consejos de alimentación que dan las mujeres de la televisión y las revistas para obtener un cuerpo } \\
\text { delgado como el de ellas. }\end{array}$ \\
\hline & 0,67 & 34 & $\begin{array}{l}\text { Cuando está de moda una prenda y me queda más apretada de lo que me gustaría, trato de cambiar mi alimentación } \\
\text { para que me quede mejor. }\end{array}$ \\
\hline & 0,59 & 37 & $\begin{array}{l}\text { Dejo de comer luego de asistir a un desfile o ver programas en la televisión en que aparecen mujeres delgadas y } \\
\text { atractivas, para intentar obtener su tipo de cuerpo. }\end{array}$ \\
\hline & 0,67 & 40 & Mi alimentación está influida por las dietas incluidas en las revistas y en los medios de comunicación en general. \\
\hline & 0,70 & 43 & Dejo de comer algunas comidas para que se me vea mejor esa prenda de ropa que todas mis amigas usan. \\
\hline & 0,61 & 49 & Siento culpa después de comer porque pienso que esas mujeres que admiro nunca comerían así. \\
\hline & 0,68 & 54 & $\begin{array}{l}\text { Soy muy exigente conmigo misma a la hora de comer, haciendo muchos esfuerzos y restricciones para parecerme } \\
\text { a las mujeres que salen en las revistas, en la televisión y en cualquier medio de comunicación. }\end{array}$ \\
\hline \multirow{12}{*}{$\begin{array}{l}\text { Objetivación del } \\
\text { cuerpo }\end{array}$} & 0,64 & 23 & Busco ser igualmente atractiva sexualmente que las mujeres que aparecen en la televisión y revistas. \\
\hline & 0,59 & 24 & Me preocupa cuando los demás no me encuentren sexualmente atractiva. \\
\hline & 0,75 & 32 & Busco vestirme de un modo provocativo para ser aceptada por los demás. \\
\hline & 0,69 & 33 & Me siento bien conmigo misma cuando me visto sexy y atractiva como las mujeres de la televisión y revistas. \\
\hline & 0,68 & 38 & Me pongo mal si los hombres no me miran admirando mi cuerpo. \\
\hline & 0,65 & 39 & Valoro mi apariencia de acuerdo a como me miran los varones. \\
\hline & 0,69 & 44 & Me siento mal si creo que mi cuerpo no tiene atractivo sexual. \\
\hline & 0,77 & 45 & Uso prendas que hacen lucir mi cuerpo sexualmente. \\
\hline & 0,76 & 47 & Me gusta que mi apariencia refleje mi atractivo sexual. \\
\hline & 0,42 & 48 & Me siento presionada por mis amigas para vestirme de manera provocativa. \\
\hline & 0,50 & 50 & Las vestimentas que no son provocativas no me gustan. \\
\hline & 0,47 & 51 & Creo que las mujeres que no son provocativas en su apariencia y gustos no son atractivas para los hombres. \\
\hline
\end{tabular}


factores. Por este motivo fueron retirados del cuestionario quedando así un total de 52 reactivos. Además 7 de los reactivos restantes $(2,5,10,13,14,16$ y 19) tenían un comportamiento ambiguo que se presentaba a través de cargas factoriales con pesos semejantes en dos de los tres factores extraídos. Luego de una revisión exhaustiva de dichos reactivos y en la búsqueda de la construcción de un instrumento libre de ambigüedades, se decidió eliminar dichos reactivos, por lo que el instrumento quedó finalmente conformado por 45 reactivos.

Una vez extraídos estos reactivos, se realizó el análisis de Factores Principales considerando la matriz de correlación policórica constituida por las 45 variables que dan origen a los 45 reactivos. Se observó que se mantenía la extracción de 3 factores principales, lo que se ratificaba con la aplicación de la rotación varimax. En definitiva, se obtuvo que los tres factores principales extraídos explicaban un $87.87 \%$ de la estructura de correlación de las variables originales, donde el aporte individual de los tres factores extraídos era de un $33.05 \%, 31.49 \%$ y $21.88 \%$ respectivamente.

Factor 1: Los reactivos que compusieron el factor 1 hacían referencia a las alteraciones en la dieta que presentan las adolescentes. A este factor se le denominó dieta patológica. Los reactivos que constituyeron este factor eran: 6,7 , $11,12,17,18,25,28,29,30,35,36,41,42,46,52$.

Factor 2: Los reactivos del factor 2 aludían a la falta de conformidad que presentan las adolescentes con su cuerpo. A este factor se le denominó disconformidad corporal. Los reactivos que constituyeron este factor eran: $1,3,4$, 8, 9,15, 20, 21, 26, 27, 31, 34, 37, 40, 43, 49 y 54. Factor 3: Los reactivos que componían este factor se orientaban a medir el grado de objetivación o erotización corporal que presentaban las adolescentes, por lo que este factor se denominó objetivación del cuerpo. Los reactivos que conformaron este factor fueron: $23,24,32,33,38,39,44$, 45, 47, 48, 50 y 51 .

En la Tabla 4 se describen las comunalidades de los distintos reactivos que cargaron en alguno de los tres factores extraídos, luego de realizar la rotación varimax.

La Tabla 5 presenta los pesos factoriales obtenidos luego de la realización de una rotación varimax para cada uno de los 45 reactivos agrupados según factor.

Una vez realizado el Análisis de Factores se realizó una comparación de los resultados del cuestionario según las diversas estratificaciones que fueron consideradas en la muestra con el fin de conocer si se presentaban distintos comportamientos en las adolescentes según las dimensiones del cuestionario.

Para todas las comparaciones de grupos realizadas se utilizó el test No paramétrico de Kuskal-Wallis y un nivel de significación de 0.05 . Al considerar el cuestionario con puntuación completa de los 45 reactivos, no existe diferencia significativa en las puntuaciones totales según nivel socioeconómico, tipo de colegio mixto y no mixto o según régimen colegio ya sea religioso o laico.

Al realizar un análisis similar para los puntajes obtenidos en cada uno de los tres factores, no se encuentran diferencias significativas en los puntajes medianos obtenidos en los tres niveles socioeconómicos, tipo de colegio o según régimen colegio para las dimensiones Dieta Patológica y Disconformidad Corporal. Sin embargo, en el subcuestionario constituido por los 12 reactivos que miden Objetivación Corporal no hay diferencias significativas en los puntajes medianos según tipo o régimen de colegio, ni en los niveles bajo y alto, pero el grupo del nivel socioeconómico medio tiene un comportamiento significativamente diferente a los otros dos niveles socioeconómicos.

Esta información se aprecia en la Tabla 6.

\section{Estimación de la Consistencia Interna}

Para obtener la consistencia interna del cuestionario, se calculó el coeficiente alfa de Cronbach tomando en cuenta los 45 reactivos finales. El valor obtenido para el instrumento completo fue de un 0.97. Al determinar el mismo coeficiente para cada uno de los tres factores extraídos en $\mathrm{AEF}$, los valores obtenidos fueron 0.97 para el conjunto de 16 reactivos agrupados en el primer factor, 0.97 para el conjunto de 17 agrupados en el segundo factor y de 0.92 para el conjunto de 12 reactivos agrupados en el tercer factor. Los valores obtenidos revelaron una alta consistencia en la totalidad de los reactivos que componen el instrumento. Asimismo, se apreció una alta consistencia al agrupar los reactivos por cada uno de los factores extraídos.

\section{Discusión}

El objetivo de esta investigación fue elaborar una escala para evaluar el impacto que las imágenes femeninas presentadas por los medios de comunicación tienen sobre las adolescentes (IMAMIF). Para la redacción de los reactivos se consideraron tres dimensiones (disconformidad corporal, dieta patológica y objetivación del cuerpo) que aparecen frecuentemente descritas en la literatura como variables implicadas en el desarrollo de la autopercepción e imagen corporal de las adolescentes.

El análisis realizado tuvo un carácter exploratorio y no confirmatorio, ya que se pretendía evaluar la validez de constructo del instrumento, sin imponer un modelo teórico, y observar si en éste se reflejaban las dimensiones del modelo propuesto por los autores.

Para estimar la consistencia interna del IMAMIF, así como evaluar la validez de constructo, a través del análisis factorial exploratorio, se constituyó una muestra de 662 adolescentes mujeres de establecimientos educacionales mixtos/no mixtos y laicos/religiosos que cursaban séptimo básico, primero medio y tercero medio, cuya edad promedio 
Tabla 6 . Análisis comparativo de puntuaciones del cuestionario final según subescala y según puntaje total estratificado por NSE, Tipo de colegio y Régimen de colegio

\begin{tabular}{llllll}
\hline Subcuestionario & Estrato & Categoría & Mín. & Mediana & Máx. \\
& & & & \\
\hline \multirow{2}{*}{ Dieta Patológica } & \multirow{2}{*}{ NSE } & Alto & 16 & 35 & 77 \\
& & Medio & 16 & 34 & 80 \\
& \multirow{2}{*}{ Tipo colegio } & bajo & 16 & 35 & 80 \\
& & Mixto & 16 & 33 & 80 \\
& & No mixto & 16 & 35 & 80 \\
& Régimen Colegio & Laico & 16 & 33 & 80 \\
& & Religioso & 16 & 35 & 80
\end{tabular}

Disconformidad corporal

$\begin{array}{lllll} & \text { Alto } & 17 & 33 & 83 \\ \text { NSE } & \text { Medio } & 17 & 30 & 84 \\ & \text { Bajo } & 17 & 32 & 85 \\ \text { Tipo colegio } & \text { Mixto } & 17 & 31 & 84 \\ & \text { No mixto } & 17 & 32 & 85 \\ \text { Régimen Colegio } & \text { Laico } & 17 & 31 & 85 \\ & \text { Religioso } & 17 & 32 & 85\end{array}$

Objetivación Corporal

\begin{tabular}{lllll} 
& Alto & 12 & 24 & 49 \\
NSE & Medio & 12 & $22(* *)$ & 57 \\
& Bajo & 12 & 25 & 56 \\
Tipo colegio & Mixto & 12 & 24 & 57 \\
& No mixto & 12 & 24 & 56 \\
\multirow{2}{*}{ Régimen Colegio } & Laico & 12 & 24 & 57 \\
& Religioso & 12 & 23 & 56
\end{tabular}

Cuestionario con 45 reactivos

\begin{tabular}{lllll} 
& Alto & 45 & 92 & 195 \\
NSE & Medio & 46 & 85 & 205 \\
& Bajo & 47 & 92 & 214 \\
Tipo colegio & Mixto & 47 & 89 & 205 \\
& No mixto & 45 & 91 & 214 \\
\multirow{2}{*}{ Régimen Colegio } & Laico & 45 & 89 & 205 \\
& Religioso & 46 & 91 & 214
\end{tabular}

(**) El test de Kruskal-Wallis indica que la mediana del NSE Medio es significativamente distinta a las de NSE Alto y Bajo (p<0.00001)

fue 14.2 con una desviación estándar de 1.7. El carácter no probabilístico de la muestra, junto con el hecho que las alumnas encuestadas provenían sólo de establecimientos educacionales, hizo que el comportamiento evaluado en relación al impacto de las imágenes femeninas presentadas por los medios de comunicación, no deba considerarse como una proyección representativa al conjunto de estudiantes escolares del país. El rango de edad considerado en la muestra corresponde al que tradicionalmente la literatura describe como la etapa del desarrollo en la que se producen los cambios puberales que afectan la percepción del propio cuerpo y la imagen corporal.
Es importante considerar que las adolescentes de la muestra correspondían a alumnas de establecimientos educacionales y no a una población consultante, lo que permite comprender la dispersión de puntajes obtenidos en la escala. Se desprende de esto la conveniencia de continuar estudiando la escala en jóvenes adolescentes que sí forman parte de población consultante.

Al considerar el cuestionario con puntuación completa de los 45 reactivos, según test de Kruskal-Wallis, no existe diferencia significativa en las puntuaciones totales según nivel socioeconómico. Al realizar un análisis similar para los puntajes obtenidos en cada uno de los tres factores, no se 
encuentran diferencias significativas en las dos dimensiones Dieta Patológica y Disconformidad Corporal ( $p>0.05$ ) en la mediana de las puntuaciones obtenidas en los tres niveles socioeconómicos. Sin embargo, en el factor Objetivización Corporal la puntuación mediana es significativamente menor en el nivel socioeconómico medio que en los niveles alto y bajo. En esta etapa de la investigación no resulta claro explicar esta diferencia observada en el nivel socioeconómico medio. Sin embargo, futuras investigaciones debieran considerar este hallazgo al estratificar la muestra.

$\mathrm{Al}$ considerar un análisis según tipo de colegio mixto y no mixto, no se apreciaron diferencias significativas, ni en los puntajes totales del cuestionario, ni en los proporcionados por cada una de las tres dimensiones. Se encontraron similares resultados, es decir, no hubo diferencias significativas al considerar muestras estratificadas según régimen colegio, ya sea religioso o laico, y considerar los puntajes totales o de las correspondientes dimensiones.

Se calculó el alfa de Cronbach de la IMAMIF y éste reveló una alta consistencia interna (0.969). De estos resultados se desprende que las jóvenes mostraron una alta coherencia en sus respuestas; aspecto fundamental a considerar si se piensa que el instrumento fue construido para continuar la investigación sobre el impacto de las imágenes femeninas presentadas por los medios de comunicación en jóvenes adolescentes. Desde el punto de vista de la validez, se estimó la validez de contenido del instrumento a partir de la evaluación de 5 jueces y, además, se realizó un análisis multivariado para evaluar la validez de constructo de acuerdo a las dimensiones del modelo teórico planteado por los autores. Para ello se llevó a cabo específicamente un análisis factorial exploratorio a través del método de extracción de factores principales, que permitió la extracción de un conjunto reducido de factores comunes que explicaban la estructura de correlación de las variables originales. En un primer análisis se extrajeron 4 componentes que explicaban un $85.49 \%$. Luego de una rotación varimax se extrajeron 3 factores, que explicaban individualmente un $32.77 \%$, $31.13 \%$ y $20.21 \%$ de la estructura de correlación existente de las variables originales.

Dado lo anterior se retiraron 9 reactivos, debido a una baja comunalidad (reactivos 22 y 53) o bien a la ambigüedad al cargar por igual en dos de los factores (reactivos 2 , $5,10,13,14,16$ y 19). Teniendo esto en cuenta se propuso que el primer factor estuviese constituido por la dimensión, "dieta patológica", el segundo factor por la dimensión "disconformidad corporal", y el tercer factor por la dimensión "objetivación del cuerpo".

Es así, que finalmente se propuso una estructura de tres factores: "Dieta Patológica", "Disconformidad Corporal" y "Objetivación del cuerpo", que en conjunto explicaba el $84.11 \%$ de la estructura de correlación entre las variables latentes medidas categóricamente a través de las puntuaciones de los individuos frente al test. Este valor se considera muy bueno.
El factor 1, "Dieta Patológica", explicaba el $32.77 \%$ de la estructura de correlación de las variables originales. Este factor refleja la dimensión más conductual y más observable del impacto que los medios de comunicación ejercen sobre las adolescentes. El factor 2, "Disconformidad Corporal", dio cuenta del $31.13 \%$ explicado de la estructura de correlación total. En los aportes de Akhtar (1992) es posible encontrar un sustento para este factor. Plantea que parte del proceso de lograr una identidad involucra la dimensión de la imagen corporal. En esta línea, una imagen realista del propio cuerpo involucra una percepción objetiva y estable de los diferentes aspectos asociados, como peso y formas. Implica también una preocupación normal por sus dimensiones y talla, con un sentimiento prevalente de satisfacción. La imagen corporal realista es señal, por lo tanto, de una adecuada relación psíquica con el propio cuerpo. Por otro lado, este factor es el que predice con mayor fuerza la génesis de psicopatología relacionada con la conducta alimentaria (Archibald, Graber \& Brooks-Gunn, 1999; Franko \& Omori, 1999; Leon, Fulkerson, Perry \& Cudeck, 1993 en Akos y Levit, 2002). El factor 3, "Objetivación del Cuerpo" explicó $20.21 \%$ de la estructura de correlación total de las variables originales. La erotización a la cual son expuestas las niñas lleva a que ellas sean más proclives a desarrollar distintos tipos de psicopatología, dentro de las cuales se cuentan más frecuentemente los trastornos de la conducta alimentaria, que implican una disconformidad corporal. Es así que la sexualización y la objetivación del cuerpo van de la mano con una imagen corporal distorsionada. La literatura describe una íntima relación entre la autoobjetivación (como rasgo en que el individuo ha internalizado fuertemente los estándares sociales del cuerpo ultra delgado, tonificado y sexualizado, creando una fijación persistente en su apariencia) y los sentimientos asociados a la falta de conformidad con el propio cuerpo (Melbye, 2007).

Podemos afirmar que se logró un primer objetivo de esta investigación al comprobarse la validez de constructo de la prueba, ya que se ajusta al modelo teórico propuesto por los autores. Sin embargo, queda aún por investigar la validez de criterio y predictiva de la escala. Con respecto a la validez de criterio, en el estado actual de la investigación de la escala y a partir de los puntajes obtenidos, sólo se puede concluir si las adolescentes presentan o no dieta patológica, disconformidad corporal y/u objetivación del cuerpo, cuando son confrontadas con las imágenes femeninas propuestas por los medios de comunicación. Sin embargo, no se puede establecer si dicho grado de impacto indica algún grado de psicopatología, difusión de identidad o alteración en la formación de una identidad sólida. Para poder aclarar lo anterior sería necesario contar con un criterio de validez externo, que podría ser incluir en la muestra una población clínica, diagnosticada por expertos, que presenten alteraciones en relación con su imagen corporal, es decir, realizar un estudio con una muestra normal y otra patológica. De este 
modo, se podrían establecer puntajes de corte que permitan discriminar si el impacto de las imágenes femeninas presentadas por los medios de comunicación ha provocado una conducta de dieta, disconformidad corporal o erotización del cuerpo. El estudio de validez predictiva es una tarea por hacer dado que sería una forma de esclarecer si el impacto de las imágenes femeninas propuesto por los medios de comunicación, observado y cuantificado en la adolescencia, se mantiene, aumenta o disminuye al transcurrir los años. Para esto se requeriría un estudio longitudinal o de seguimiento. Otra tarea pendiente es realizar la comparación de medias de los resultados del cuestionario en los distintos tipos de establecimientos educacionales, sean estos de tipo mixto o no y de formación laica o religiosa. También queda el desafío de plantear un modelo teórico considerando los resultados obtenidos en este estudio exploratorio, y de aplicar la metodología de Análisis Factorial Confirmatorio a través de ecuaciones estructurales. Este análisis permite introducir una estructura de correlación entre las dimensiones que subyacen al modelo.

A modo de síntesis, la escala que se presenta en este trabajo constituye un paso hacia la comprensión del impacto del ideal de belleza femenina propuesto por los medios de comunicación en las adolescentes, además de proporcionar un instrumento válido y confiable para medir dicho impacto.

\section{Referencias}

Aguirre, M.E. (Ed.) (2006). Ser Padres de Adolescentes hoy. Santiago: Universidad de los Andes, Instituto de Ciencias de la Familia.

Aiken, L.R. (1996). Test psicológicos y evaluación. México, Nueva York: Prentice Hall, Hispanoamericana, S. A.

Akhtar, S. (1992). Broken structures: severe personality disorders and their treatment. London: Jason Aronson.

Akhtar, S. \& Samuel, S. (1996). The concept of identity: developmental origins, phenomenology, clinical relevance, and measurement. Harvard Review of Psychiatry, 3, 254-267.

Akhtar, S. (2003). New clinical realms: Pushing the envelope of theory and technique. New Jersey: Jason Aronson Inc.

Akos, P. \& Levitt, H. (2002). Promoting healthy body image in middle school. Professional School Counseling, 6, 138-144.

American Psychological Association, Task Force on the sexualization of Girls (2007). Report of the APA Task Force on the sexualization of girls Washington, D.C.: American Psychological Association. Extraido el 30 de mayo de 2007, desde www.apa.org./pi/wpo/sexualization.html.

Anderson, R. \& Pempek, T. (2005). Television and very young children. American Behavioral Scientist, 48, 505-522

Bardone-cone, A. \& Cass, K. (2006). Investigating the impact of proanorexic websites: A pilot study. European Eating Disorders Review, 14, 256-262.

Behar A. R., De la Barrera C.M. y Michelotti C.J.(2000) Identidad de género y trastornos de la conducta alimentaria. Revista Médica de Chile, 129, 1003-1011.

Bonelli, R. (2007). Fashion, lifestyle and psychiatry. In A.M. González \& L.Bovone (eds), Fashion and identity: A multidisciplinary approach, 157-178. Barcelona: Social Trends Institute.

Brumberg, J. J. (1997). The body project: an intimate history of american girls. New York:Vintage.
Calogero, R.M. (2004). A test of objectification theory: The effect of the male gaze on appearance concerns in college women. Psychology of Women Quarterly, 28, 16-21.

Casper, R.C. \& Offer, D. (1990). Weight and dieting concerns in adolescents: fashion or symptom? Pediatrics, 86, 238-241.

Castilla \& Cortázar, B. (1996). Persona Femenina y Persona Masculina, Madrid: Rialp.

Castilla \& Cortázar, B. (1997). Persona y Género: ser varón y ser mujer, Barcelona: Ediciones Internacionales Universitarias.

Choza, J. (1988). Manual de Antropología Filosófica, Madrid: Rialp.

Correa, M., Zubarew, T., Silva P., \& Romero, I. (2006). Prevalencia de riesgo de trastornos alimentarios en adolescentes mujeres escolares de la Región Metropolitana. Revista Chilena de Pediatría, 77, 153-160.

Cullari, S., Vosbug, M., Shotwell, A., Inzodda, J. \& Davenport, W. (2002). Body image assessment: A review evaluation of a new computer-aide measurement technique. North American Journal of Psychology, 4, 221-232.

Cullari, S., Rohrer, J., \& Bahm, C. (1998). Body-image perceptions across sex and age groups. Perception and Motors Skills, 87, 839-847.

Dasgupta, N. \& Asgari, S. (2004). Seeing is believing: Exposure to counterstereotypic women leaders and its effect on automatic gender stereotyping. Journal of Experimental Social Psychology, 40, 642- 658.

Diaz, P., Pandolfi, P., \& Perfetti, R. (1999). Atractivo físico. Apsique. Extraído el 15 de julio de 2006, desde www.apsique.com.

Doltó, F. (1990). La causa de los adolescentes: el verdadero lenguaje para dialogar con los adolescentes. Barcelona: Seix Barral.

Eco, U. (2004). Historia de la belleza. Barcelona: Lumen.

Eco, U. (2007). Historia de la fealdad. Barcelona: Lumen.

Fallon, A.E. \& Rozin, P. (1985). Sex differences in perceptions of desírable body shapes, Journal of Abnormal Psychology, 94, 102-105.

Franko, D. \& Omori, M. (1999). Subclinical eating disorders in adolescent women: a test of the continuity hypothesis and its psychological correlates. Journal of Adolescence, 22, 389-396.

Fredrickson, B.L. \& Roberts, T.A. (1997). Objectification theory: Toward understanding womens lived experiences and mental health risks. Psychology of Women Quarterly, 21, 207-226.

Fredrickson, B.L., Roberts, T.A., Noll, S.M., Quinn, D.M., \& Twenge, J.M. (1998). That swimsuit becomes you: Sex differences in selfobjectification, restrained eating, and math performance. Journal of Personality and Social Psychology, 75, 269-284.

González, A.M. \& Bovone, L. (Eds.) (2007). Fashion and identity: A multidisciplinary approach, Barcelona: Social Trends Institute.

Graber, J. A., Archibald, A. B., \& Brooks-Gunn, J. (1999). The role of parents in the emergence, maintenance, and prevention of eating problems and disorders. In N. Piran, M. P. Levine, \& C. Steiner-Adair (Eds.), Preventing eating disorders: A handbook of interventions and special challenges, Philadelphia: Brunner/Mazel.

Herreros, M. (2002). La moda en la postmodernidad. Humanitas, 27, 392-403.

Kroger, J. (2000). Identity development, adolescence through adulthood. California: Sage Publications.

Larraín, M.E. (2007). Adolescence: identity, fashion and narcissism. En A.M.González \& L. Bovone (Eds), Fashion and identity: A multidisciplinary approach, 135-154. Barcelona: Social Trends Institute.

Marín, V. (2002). Trastornos de la conducta alimentaria en escolares y adolescentes. Revista Chilena de Nutrición, 29, 86-91.

Melbye, L., Tenenbaum, G. \& Eklund, R. (2007). Self-objectification and exercise behaviors: The mediating role of social physique anxiety. Journal of Applied Biobehavioral Research, 12, 196-220.

Molt, R.W. \& Conroy, D. E. (2000). Confirmatory factor analysis of the physical self-Efficacy scale with a college-aged sample of men and women. Measurement in Physical Education and Exercise Science, 4, 13-27.

Panter, A. T., Swygert, K. A., Dahlstrom, W. G. \& Tanaka, J. S. (1997). Factor analytic approaches to personality item-level data. Journal of Personality Assessment, 68, 561-589. 
Pinhas, L., Toner, B.B., Ali, A., Garfinkel, P.E. \& Stuckless, N. (1999). The effects of the ideal of female beauty on mood and body satisfaction. International Journal of Eating Disorders, 25, 223-226.

Ricciardelli, M. \& McCabe, L. (2001). Self-Esteem and Negative Affect as Moderators of Sociocultural Influences on Body Dissatisfaction, Strategies to Decrease Weight, and Strategies to Increase Muscles Among Adolescent Boys and Girls. Sex Roles, 44, 189-207.

Roberts, T. \& Gettman, J.Y. (2004). Mere exposure: Gender differences in the negative effects of priming a state of self-objectification. Sex Roles, 51, 17-27.

Salomone, R.( 2003). Same, different, equal: re-thinking single sex schooling, New Haven: Yale University Press.

Simmons, L. \& Blyth, D. (1987). Moving into Adolescence: The Impact of Puberal Change and School Context. Social institutions and social change. New York: A. de Gruyter.

SIMCE (2004). Clasificación según grupo socio económico. Extraído el 15 de marzo de 2006, desde www.consejogestionescolar.cl/pdf/ clasi_SIMCE.pdf.
Sypeck, M., Grey, J. \& Ahrens, A. (2004). No longer just a pretty face: Fashion magazine's depictions of ideal female beauty from 1959 to 1999. International Journal of Eating Disorders, 36, 342-347.

Thomsen, S.; McCoy, K. \& Williams, M. (2001). Internalizing the impossible: Anorexic outpatient's experiences with women's beauty and fashion magazines. Eating Disorders, 9, 49-64.

Tiggerman, M., \& McGill, B. (2004). The role of social comparison in the effect of magazine advertisements on women: mood and body dissatisfaction. Journal of Social and Clinical Psychology, 23, 23-44.

Tiggermann, M, \& Lynch, J.E. (2001). Body image across the life span in adult women: The role of self-objectification. Developmental Psychology, 37, 243-253.

Tiggerman, M. \& Slater, A. (2004). Thin ideals in music television: a source of social comparison and body dissatisfaction. The International Journal of Eating Disorders, 35, 48-58. 